\title{
Los pueblos indígenas y sus derechos sobre la tierra en Venezuela: entre la modernidad y la colonialidad
}

Os povos indígenas e seus direitos sobre a terra na Venezuela: entre a modernidade e a colonialidade

\author{
Yheicar Bernal Rodriguez \\ Magíster en Estudios Culturales. \\ Investigador del Laboratorio de Antropología del Desarrollo del Instituto Venezolano de Investigaciones \\ Científicas -IVIC \\ e-mail: yheicar@gmail.com
}

\begin{abstract}
Resumo
A partir das categorias analíticas do debate descolonizador, neste trabalho ressalto os condicionamentos geopolíticos e geoepistêmicos que subjazem ao processo de reconhecimento, na Constituição da República Bolivariana da Venezuela, dos direitos coletivos sobre a terra. Iniciado em 1999, dito processo reconheceu a ancestralidade da ocupação territorial pelos povos indígenas. Destaca-se que uma década depois desse reconhecimento constitucional surgiu uma dinâmica intensa de demarcações de terras no país.
\end{abstract}

Palavras-chave: Venezuela, direitos territoriais indígenas, debate descolonial, cartografia, autodemarção.

\section{Resumen}

A partir de las categorías analíticas interpretativas del debate decolonial, este trabajo evidencia algunos de los condicionamientos geopolíticos y geoepistémicos del reconocimiento de los derechos colectivos sobre la tierra en la Constitución de la República Bolivariana de Venezuela. Ese proceso que se inició en el año de 1999, reconoció la ancestralidad de la ocupación territorial de los pueblos indígenas. Una década después ha derivado en una serie de demarcaciones de tierras y en la elaboración de mapas.

Palavras-clave: Venezuela, derechos territoriales indígenas, debate decolonial, cartografía, autodemarcación.

\section{Introducción}

En este trabajo a partir de la reflexión decolonial estableceré algunas de las paradojas que se desprenden del reconocimiento de los derechos sobre las tierras indígenas por parte del Estado venezolano. En medio de este debate han surgido una serie de categorías analítico-interpretativas por medio de las cuales trataré de señalar cómo operan ciertos dispositivos geoepistemológicos en el Estado-nación y en ciertas disciplinas como la cartografía. 
En materia de derechos indígenas, la Constitución de 1999 sobresale de todas las anteriores ${ }^{1}$ ya que supera la tradición del siglo XIX, la cual concebía la idea de una nación única y unitaria desde el punto de vista cultural y étnico. La política del Estado, antes del año 1999, estaba basada en una visión integracionista - asimilacionista, mediante la cual se llevaba a cabo un proceso de incorporación progresiva de los indígenas, como sujetos que le eran ajenos, a un modelo único de nación (Hernández, 2001, Bello, 2011).

La aprobación de la Constitución de la República Bolivariana de Venezuela (CRBV), en diciembre de 1999, representó un acontecimiento trascendente en la larga historia de lucha por el reconocimiento estatal de los derechos de los pueblos indígenas. El preámbulo de la CRBV reconoció el carácter multiétnico y pluricultural venezolano. Por otro lado, en el capítulo VIII, "Sobre los derechos de los pueblos indígenas", artículos del 119 al 126, quedó plasmado dicho reconocimiento constitucional.

Para el presente trabajo destacaré el artículo 119, principalmente lo relacionado al derecho sobre las tierras y el proceso de demarcación, cuyo contenido integral es el siguiente:

Artículo 119: El Estado reconocerá la existencia de los pueblos y comunidades indígenas, su organización social, política y económica, sus culturas, usos y costumbres, idiomas y religiones, así como su hábitat y derechos originarios sobre las tierras que ancestral y tradicionalmente ocupan y que son necesarias para desarrollar y garantizar sus formas de vida. Corresponderá al Ejecutivo Nacional, con la participación de los pueblos indígenas, demarcar y garantizar el derecho a la propiedad colectiva de sus tierras, las cuales serán inalienables, imprescriptibles, inembargables e intransferibles de acuerdo con lo establecido en esta Constitución y en la ley. (CRBV, 1999: art. 119; el subrayado es nuestro)

En este artículo de la CRBV se establece no sólo el reconocimiento de los pueblos indígenas, sino también de su organización social, política, económica, sus culturas, así como los derechos originarios sobre las tierras. También señala claramente que el Ejecutivo Nacional demarcará y garantizará el derecho a la propiedad colectiva de las tierras. En tal sentido,

\footnotetext{
${ }^{1}$ Venezuela desde su independencia en 1811 hasta el presente ha tenido formalmente 26 constituciones, incluyendo el Acta de la Independencia del 5 de julio de 1811 y la Constitución de la República Bolivariana de Venezuela de 1999.
} 
una serie de instituciones e instrumentos jurídicos han sido elaborados con el objetivo de regir los procedimientos para dar cumplimiento al mandato constitucional.

De acuerdo con la nueva Constitución, los pueblos indígenas son parte de la nación, y se les reconocen sus derechos especialmente sobre la tierra. Este reconocimiento condujo a demarcaciones y autodemarcaciones de tierras indígenas conllevando también, entre otras cosas, a la realización de mapas. Por eso, desde una perspectiva decolonial, pretendo tensionar analíticamente ese reconocimiento, el procedimiento de la demarcación y la elaboración de mapas. Se espera que este análisis revele los condicionamientos geopolíticos y geoepistémicos que subyacen a ese reconocimiento constitucional así como las paradojas jurídicas y políticas que surgen, luego de más de una década de existencia de este proceso.

\section{El debate decolonial: breve contextualización}

La reflexión decolonial se viene formulando a partir del trabajo de distintos autores latinoamericanos que han problematizado la modernidad y particularmente sobre el significado de dicha experiencia a través de la perspectiva de quienes la han vivido desde una condición subalterna (Restrepo, 2010). En estas líneas no pretendo dar un panorama sobre este proyecto de investigación latinoamericano en curso, sólo tomaré algunas de sus categorías para analizar el caso que nos ocupa ${ }^{2}$.

Una de las formulaciones que da cuerpo al debate decolonial es la de modernidad/colonialidad. Mientras la modernidad en Europa promovió la retórica de la emancipación y los derechos, ella misma prescribe, a través del proceso de la colonialidad, sobre el resto del mundo una estrategia de dominio y control que implica la supresión de muchas formas de conocer.

La categoría modernidad/colonialidad permite poner en evidencia cómo el diseño global de una civilización se extendió desde Europa al resto del mundo y con ello generó la mundialización de una cultura dominante ocultando la existencia de otras múltiples historias locales que se suceden

\footnotetext{
2 Esta colectividad de argumentación está conformada por Aníbal Quijano, Walter Mignolo, Edgardo Lander, Ramón Grosfoguel, Santiago Castro-Gómez, Fernando Coronil y Eduardo Restrepo, entre otros autores. Arturo Escobar (Escobar, 2003) utiliza la expresión programa de investigación para referirse al trabajo de dicho grupo. Escobar señala que el trabajo del programa de investigación busca intervenir decisivamente en la discursividad propia de las ciencias modernas para configurar otro espacio para la producción de conocimiento - una forma distinta de pensamiento, un paradigma otro, la posibilidad misma de hablar sobre mundos y conocimientos de otro modo. Walter Mignolo (2003) se refiere a este debate como la opción des-colonial, mientras que Eduardo Restrepo (2010) apuesta por denominarla inflexión decolonial. Para una relación de los intereses teórico prácticos del grupo, remitimos a la reseña de la trayectoria y categorías claves elaborada por Castro-Gómez y Grosfogel (2007).
} 
al mismo tiempo en distintos lugares. Asimismo, esta categoría también permite revelar que la extensión e imposición de una macro-narrativa con un dios, una lengua, una historia e idioma, desde un espacio, Occidente, y una temporalidad, la moderna, mediante la violencia epistemológica del eurocentrismo ${ }^{3}$, ha producido la oclusión de otras formas de vivir, conocer y hacer (Mignolo, 2003). El reconocimiento de esta situación permite entrever que se trata, no sólo de un largo proceso histórico y epistemológico, sino también de un proceso político.

De acuerdo a Castro Gómez (2005a), la hybris del punto cero es una categoría del debate decolonial usada para señalar el lugar o la plataforma, supuestamente neutra, desde la que se pretende ver, conocer, clasificar y dispoer de poblaciones y recursos. La hybris del punto cero es la perspectiva del modo de conocer moderno-colonial. Mediante este dispositivo geoepistemológico se han organizado todas las disciplinas del conocimiento y la manera en que operan, clasificando, conforme a una jerarquización del tiempo y del espacio, todos los conocimientos.

La hybris del punto cero está referida tanto al ordenamiento jerárquico de conocimientos, lenguajes, memorias e imaginarios, como a la organización general tanto del tiempo y del espacio en una narrativa que se vuelve universal, con Occidente como centro espacial y la modernidad como proyecto como punto de llegada. Como lo señala Wallerstein (2001), a propósito de su análisis del eurocentrsimo en las ciencias sociales: lo que has visto ahora en Europa, no es sólo bueno sino el rostro del futuro en todas partes. La hybris del punto cero y la organización colonial del mundo llevada a cabo por la modernidad/colonialidad tienen en la dimensión espacial un fuerte desarrollo. Su conjunción posibilita el desarrollo de la mirada universal, omnisciente, absoluta, que ha configurado las disciplinas del conocimiento, como es el caso de la cartografía y también de las instituciones del orden social como el Estado-nación.

Otra categoría del debate decolonial que nos permite hacer una lectura crítica del Estado-nación es la función centro. La función centro es cierto grado de autoridad teórica que reside en el monopolio de poder de representación, según el cual, "representar" es controlar los medios discursivos que subordinan el objeto de conocimiento a una economía

\footnotetext{
${ }^{3}$ El eurocentrismo coloca a Europa como el centro con la modernidad como un fenómeno intra-europeo, es decir, con origen y desarrollo dentro de Europa. El centro se impone como tal y configura unas periferias a las que irradia, entre otras cosas, su tiempo. Aunque como lo destaca Dussel toda cultura es etnocéntrica, el etnocentrismo, europeo, moderno es el único que puede pretender identificarse con la universalidadmundialidad.
} 
conceptual declarada superior. ${ }^{4}$ En el Estado-nación, como dispositivo de la modernidad/colonialidad, a través de sus instituciones, prácticas y discursos, opera la función centro. En el Estado-nación la función centro ejerce su capacidad de nombrar, representar, modular y hacer desarrollar en sus términos, sólo con sus condiciones, ciertos procesos como, por ejemplo, la demarcación de tierras indígenas que actualmente se lleva a cabo en Venezuela.

Mi propósito es señalar, de acuerdo al debate en torno a la modernidad/colonialidad, la hybris del punto cero y de la función centro, que existen una serie de determinaciones geohistóricas, geopolíticas y geoepistémicas que subyacen al desarrollo de los derechos sobre las tierras indígenas que el Estado venezolano intenta implementar.

Desde el punto de vista del debate decolonial, tanto el Estado-nación como el modelo de conocer moderno colonial son centrípetos y egocéntricos. El Estado-nación con su función centro se coloca en el centro, con su investidura de autoridad para nombrar y disponer de todo lo demás, con su manera ejercer el poder y de implementar los derechos. El modo de conocer moderno colonial dispone del resto hacia la periferia como la otredad tradicional que debe ser nombrada, civilizada, conquistada, dotada de sentido y georeferenciada.

El reconocimiento constitucional del derecho sobre las tierras indígenas y su demarcación en Venezuela permite poner en evidencia que su condicionamiento a la colonialidad implicando en la imposición de una sola forma de hacer, que es ejercida por el Estado-nación en uso del monopolio legítimo en la función centro y en la cartografía como técnica privilegiada de conocer $y$, en términos jurídicos, comprobar ese derecho territorial.

El derecho sobre las tierras indígenas se ve mediado por los condicionamientos que tiene el Estado-nación el cual, con su legislación, permite nombrar y visibilizar sólo en sus términos el mencionado derecho y su reconocimiento. Se impone una demarcación y la realización de mapas en los que la categoría analítica de la hybris del punto cero se coloca como evidencia técnica-científica, es decir legitima. El pretendido lenguaje universal de la ciencia se esconde y ampara en la dicha objetividad que la episteme moderna defiende para sí. Ese lugar privilegiado históricamente

\footnotetext{
${ }^{4}$ Esta crítica de la pensadora chilena Nelly Richard con fuertes raíces en Derrida, está dirigida al debate latinoamericano hecho desde la academia norteamericana. Véase Richard (1998, págs. 245-248) y Castro-Gómez, (2005b, pág. 36).
} 
ha ido dejando de lado otras perspectivas de conocimiento y representación como las formas indígenas.

La cartografía como disciplina, con sus mapas, opera en un doble sentido, por un lado, condiciona la representación mediante sus convenciones técnicas y por el otro, como representación a través de la imagen, impone un tipo de relación, la cual es, mediada, de diferencia y exterioridad. La colonialidad del poder y del saber opera a través de la cartografía determinando una relación por sobre otras y a la vez naturalizándola.

El establecimiento de este tipo de relaciones permitidas con el espacio es uno de los intereses y necesidades del Estado-nación, el cual, a su vez, es otro de los dispositivos de la modernidad/colonialidad. La cartografía, con su mapa-imagen-representación contribuye a generar cierta comunidad imaginada, en este caso la del Estado-nación, delimitando un exterior y un interior, un centro y una periferia, clasificando y jerarquizando el espacio.

No se discute la utilidad que los mapas y la cartografía puedan tener para ciertos fines relacionados con el resguardo de tierras o para el reconocimiento por parte del Estado-nación de los derechos sobre las tierras indígenas. Mi reflexión pretende instalarse en el intersticio de la modernidad/colonialidad, en el umbral del camino del cumplimiento del derecho que sería una cara de la modernidad y el despliegue de la episteme moderna a través de la función centro y de la hybris del punto cero en la otra cara.

Balance preliminar de la demarcación de tierras indígenas en el Amazonas (Venezuela)

A continuación, se describen ejemplos de cómo opera la modernidad/colonialidad, la hybris del punto cero y la función centro en el proceso de demarcación de tierras indígenas venezolano. Me centraré en los dispositivos espacializantes tales como los mapas, las demarcaciones, los planes de ordenamiento territorial, las instituciones y las leyes que sirven de mecanismos para la construcción de un tipo, en detrimento de otras maneras de construcción y legitimación territorial.

El último censo indígena de Venezuela realizado en el año 2011 reporta la existencia de 53 pueblos indígenas con una población de 724.592 
habitantes. Si el total de la población nacional es de 27.227.930 habitantes, tenemos que la población indígena representa el 2,7\% del total nacional ${ }^{5}$.

El balance del proceso de demarcación de tierras indígenas en Venezuela, en su primera década, arroja los siguientes resultados: i) hasta ahora no se han entregado títulos de propiedad colectiva de grandes dimensiones; ii) las noticias sobre la entrega de títulos en estados fronterizos son muy escazas e iii) tímida entrega de títulos en Amazonas, Bolívar y Zulia estados con presencia importante de pueblos indígenas ${ }^{6}$.

Sin embargo, de acuerdo a información suministrada por Aloha Núñez, actual ministra para los pueblos indígenas, el Estado venezolano ha otorgado hasta la fecha 87 títulos de propiedad colectiva de tierras indígenas sumando un área de 2.943.096 hectáreas, con los que se ha beneficiado a 542 comunidades indígenas ${ }^{7}$. La ministra también ha señalado que el Estado venezolano está en deuda con 21 solicitudes pendientes y están procesando 24 nuevas peticiones.

\section{Instituciones y leyes}

Conjuntamente con las demarcaciones de tierras indígenas en Venezuela se creó el año 2001 la Comisión Nacional de Demarcación del Hábitat y Tierras de los Pueblos y Comunidades Indígenas ${ }^{8}$. Entre sus primeras acciones estuvo elaborar un reglamento para la consignación de las solicitudes de demarcación que, entre otros requisitos, incluyen los mapas de las tierras indígenas, con sus límites, toponimia, información históricocultural, entre otros. El 08 de enero de 2007 fue creado el Ministerio del Poder Popular para los Pueblos Indígenas y se designó a una indígena Ye'kuana como su primera titular. ${ }^{9}$

\footnotetext{
5 Fuente Censo 2011 del Instituto Nacional de Estadística, INE, de la República Bolivariana de Venezuela.http://www.ine.gov.ve/documentos/Demografia/CensodePoblacionyVivienda/pdf/ResultadosBasicos .pdf, Revisado el 02 /03/ 2014.

${ }^{6}$ Para mayores detalles sobre la evolución de las demarcaciones de tierras en Venezuela véase Caballero, 2007.

${ }^{7}$ La información está dispersa, no hay una fuente oficial que presente la información de manera ordenada y permita tener un panorama claro con los totales de área respectivos. Para obtener mayores detalles véase: Caballero Arias, 2007; Silva Moterrey, 2009 y la página web del Ministerio del Poder Popular para los Pueblos Indígenas. http://www.minpi.gob.ve/minpi/es/noticias. Para las declaraciones de la ministra Aloha Núñez se consultó la página web de la Agencia Venezolana de Noticias www.avn.info.ve y el diario Ciudad Caracas el día 08 de enero de 2014.

${ }^{8}$ Véase Decreto No. 1392 de fecha 3 de agosto de 2001, Gaceta Oficial de la República Bolivariana de Venezuela No. 37257 de fecha 09 de agosto de 2001.Modificada mediante dos decretos uno publicado en la Gaceta Oficial No. 39624 del 25 de febrero de 2011 y otra resolución en la que se modifica la conformación de la Comisión Nacional de Demarcación del hábitat y tierras de los pueblos indígenas. Gaceta Oficial No. 39.876 del 5 de marzo de 2012.

${ }^{9}$ Según decretos publicados en la Gaceta Oficial de la República Bolivariana de Venezuela N ${ }^{\circ} 5.103$ de fecha 28 de diciembre de 2006 y en la Gaceta Oficial N 5.836 del 8 de enero de 2007.
} 
Paralelamente han sido elaborados una serie de instrumentos jurídicos dentro de los cuales destacan los siguientes: Ley de Demarcación y Garantía del Hábitat y Tierras de los Pueblos Indígenas, (2001); ratificación y aprobación del Convenio 169 sobre Pueblos Indígenas y Tribales de la OIT (2002); Ley Orgánica de Pueblos y Comunidades Indígenas, (2005); reglamento orgánico del Ministerio del Poder Popular para los Pueblos Indígenas (2007); Ley de idiomas indígenas (2008); Ley de patrimonio cultural de los Pueblos y comunidades Indígenas (2009). ${ }^{10}$ Toda esta estructura institucional y la legislación creada son de gran importancia ya que las leyes fortalecen el reconocimiento y garantizan la implementación del derecho indígena, mientras que la estructura institucional establece cuál será la instancia que ejecute la ley, es decir, promueva el desarrollo del derecho territorial indígena.

La situación actual de los derechos de los pueblos indígenas dentro del Estado-nación venezolano se encuentra en medio de varias paradojas. La primera está relacionada con la mediación del derecho por la institucionalidad y legislación señalada la cual, ejerciendo su función centro, reconoce el derecho indígena sólo en sus términos. Por otro lado, la segunda paradoja es que esta estructura institucional y el marco legal serán las que en un futuro permitirán exigir el diseño e implementación de políticas públicas que posibiliten el real cumplimiento del derecho garantizado en la Constitución obedeciendo al carácter multiétnico y pluricultural de la República Bolivariana de Venezuela.

Por otro lado, tenemos la paradoja que se deriva del posicionamiento geohistórico y geopolítico del Estado-nación venezolano y bolivariano a finales del siglo XX y comienzos del XXI en un sistema-mundo-modernocolonial. El Estado-nación venezolano mediante condicionamientos que le preceden y trascienden ya que son geohistóricos y geopolíticos, a través de la función centro ha naturalizado y universalizado cierto orden de relaciones sociales y no otras. Dentro del Estado-nación a su vez, la institucionalidad y las leyes señaladas, convertidas en tecnologías de poder y disciplina se estaría llevando a cabo un ordenamiento de la vida de los pueblos indígenas.

La demarcación de tierras indígenas cuenta con una normatividad, que más allá de reconocer, define en algunos casos, aspectos tan esenciales como las tierras indígenas, tal es el caso de la Ley Orgánica de Pueblos y Comunidades Indígenas que en su artículo 3 señala:

${ }^{10}$ Para mayores detalles jurídicos sobre estos instrumentos véase Caballero Arias (2007). 
Tierras Indígenas: son aquellas en las cuales los pueblos y comunidades indígenas de manera individual o compartida ejercen sus derechos originarios y han desarrollado tradicional y ancestralmente su vida física, cultural, espiritual, social, económica y política. Comprenden los espacios terrestres, las áreas de cultivo, caza, pesca, recolección, pastoreo, asentamientos, caminos tradicionales, lugares sagrados $e$ históricos y otras áreas a las que hayan tenido acceso tradicional y que son necesarias para garantizar y desarrollar sus formas específicas de vida. (LOPCI: art. 3)

Reconocemos que esta definición busca darle mayor precisión al objeto sobre el cual se pretende legislar. Sin embargo, queda en evidencia el proyecto civilizatorio del Estado-nación venezolano que reconoce las tierras indígenas sólo en sus términos hegemónicos, por lo que es justo preguntarse ¿cuál es la definición de tierras que tienen los pueblos indígenas? Asimismo, se debe señalar que de acuerdo a lo señalado por la CRBV y las leyes que la reglamentan, los pueblos indígenas sólo tienen derecho al hábitat y tierras ya que el territorio es la forma espacial que le corresponde a la Nación y a la República.

\section{La autodemarcación de tierras Ye'kuana del Alto Orinoco}

Mucho antes del reconocimiento de los derechos sobre las tierras indígenas plasmado en la CRBV, algunos de los pueblos indígenas de Venezuela habían llevado a cabo la autodemarcación de sus tierras. Tal es el caso del pueblo Ye'kuana del Alto Orinoco, realizada entre 1993 y 1995. Una revisión de este proceso nos permite apreciar la conjunción de distintos tipos de procedimientos y registros para su elaboración.

Para la autodemarcación de tierras Ye'kuana fue de gran importancia el mito que legitima la conformación del territorio ancestral, elaborada por Kuyujani. Este mito fue transmitido de generación en generación a través de la historia oral y nos llega a la actualidad gracias al esfuerzo del sabio Ye'kuana José Félix Turón, recientemente fallecido, y del también indígena de la misma etnia, Simeón Jiménez, quien es el traductor y exégeta:

Kuyujani habiendo salido de Ye'kuanajüdü, para demarcar las tierras que Wanadi nos había confiado, lo alcanzó Tunamö (el diluvio) a la altura del Cerro Anaicha y para salvar su vida y la de su gente, tuvo que refugiarse en ese cerro. Kuyujani inició su recorrido desde el Cuntinamo, donde está Yejuanajüdü, siguió por el Metacuni, Orinoco abajo hacia el Atabapo, pasó 
Atures, El Cataniapo y llegó a sus cabeceras hasta el cerro Anaicha. Desde allí, más tarde, partió con sus hermanas Kaddesawa, Kuyunu y Wadimena y el resto de su gente hacia Ye kuanajüdü, atravesando el cerro Washadijüdü (el Danto), las cabeceras del Ventuari, la Sierra Parima y volvió a caer en el Ye'kuanajüdü.

Fue un largo caminar, y a su regreso, Kuyujani, con toda su gente se metió en las entrañas del cerro de los Ye'kuana; regresará de nuevo a vivir sobre la tierra como nos lo prometió (Jiménez y Perozo, 1994: 12).

El mito que recoge el viaje de Kuyujani tiene una descripción de los linderos de las tierras Ye'kuana del Alto Orinoco. En sí mismo, constituye una propuesta de recorrido por/sobre el límite del territorio, una narración que a la vez es una invitación al viaje a través de las tierras Ye'kuana, mientras lo organiza, lo cartografía, mediante la selección y agrupación de hitos.

De Certeau (2007) ha señalado que en los mapas medievales se representaba a través de líneas, los recorridos generalmente vinculados con los peregrinajes. Las etapas y las distancias eran señaladas con relación a unidades temporales expresadas en días y jornadas, es decir, en tiempos de camino. El mapa se convertía en un memorando que prescribía acciones. Con la evolución del pensamiento y técnicas de representación cartográfica, el mapa se aleja de su presentación como itinerario y pasa a ser más una totalización, un dispositivo de control.

En el proceso de autodemarcación llevado a cabo, entre 1993 y 1995, fue representado mediante un mapa histórico cultural amparado en la oralidad Ye'kuana. En la parte superior del mapa Ye'kuana consta la siguiente nota:

"Mapa histórico cultural realizado por los Ye kuana de los ríos Cunucunuma, Cuntinamo y Padamo en feb. De 1994, en el cual deslindan el territorio que Kuyujani les dejó en custodia. Superpuesto a un mapa de la misma zona, es de resaltar la asombrosa precisión con la cual los Yékuana conocen los límites y accidentes geográficos de sus tierras ancestrales." Jiménez \& Perozo (1994: 21-22)

El mapa Ye'kuana fue publicado ${ }^{11}$ junto con aquel elaborado por un geógrafo. La construcción de esos mapas inició con el trabajo en el terreno realizado por hombres y mujeres Ye'kuana de varias comunidades del

${ }^{11}$ Idem, 21,22 
municipio Alto Orinoco. Permitió marcar una serie de círculos ubicados en el perímetro de sus tierras, considerados vitales. Luego un geógrafo georeferenció desde el aire, en vuelo con avioneta, obteniendo así la primera silueta del territorio Ye'kuana. En este caso, la conjunción de mito, trabajo de indígenas sobre sus tierras, así como la intervención de geógrafos, permitió elaborar el mapa de las tierras Ye'kuana del Alto Orinoco. ${ }^{12}$

La presentación y utilización de los mapas está operando la hybris del punto cero tal y como se ha definido aquí. En la lógica del conocimiento colonial el mapa Ye'kuana pudiera ser visto como doxa, carente de conocimiento científico técnico. Su valor funciona apenas para legitimar el rigor de los instrumentos de la ciencia. Esta crítica podría extenderse a cierta moda, relativamente común entre los antropólogos, que legitiman la apariencia y técnica de ciertos mapas ingenuos, vueltos fetiches y objetos de consumo. Esa legitimación acrítica del conocimiento occidentalmoderno- opera como estrategia moderna de colonizar el saber, principalmente de los pueblos indígenas.

Sin embargo, el proceso de autodemarcación Ye'kuana crea horizontes de posibilidad donde emergen las perspectivas indígenas. Esta puede asomarse en el cruce de registros orales, visuales y del trabajo en campo. Allí mismo en el seno de una operación de la modernidad/colonialidad como lo es la demarcación y el mapeo.

\section{Fronteras y límites sobre las tierras Yanomami}

La demarcación de tierras indígenas como expresión del derecho al territorio de los pueblos indígenas en el Amazonas, al sur de Venezuela, enfrenta un entramado de figuras jurídicas. El ordenamiento territorial venezolano se solapa sobre las tierras que ocupan estos pueblos indígenas. Estas figuras jurídicas territoriales pudieran afectar la demarcación de tierras del pueblo indígena Yanomami, el cual habita entre varios límites y fronteras nacionales, por ejemplo. Cuatro figuras de ordenamiento jurídico territorial se yuxtaponen y afectan directamente las tierras Yanomami:

A) Límites internacionales entre la República Bolivariana de Venezuela y la República Federativa del Brasil; B) Los límites estadales entre los estados venezolanos de Amazonas y Bolívar; C) limites municipales de los municipios Alto Orinoco y Río Negro (Amazonas) y Sucre y Raúl Leoni

\footnotetext{
${ }^{12}$ Para más detalles sobre este proceso véase Jiménez y Perozo (1994).
} 
(Bolívar); D) las áreas protegidas que se dividen en varios subgrupos: parques nacionales; monumentos naturales; y la reserva de biosfera..$^{13}$

Estas figuras de ordenamiento territorial generan diferentes nociones de límites y fronteras - internacionales, estadales, municipales, de áreas protegidas -, que ignoran la comprensión territorial del pueblo Yanomami. Para el Estado-nación venezolano el establecimiento de sus fronteras, límites y delimitaciones territoriales son manifestaciones de poder y del ejercicio de su soberanía nacional. Se busca establecer claramente, tanto hacia el interior, es decir, para sus ciudadanos e instituciones, como hacia el exterior, es decir, para sus vecinos y la comunidad mundial, la eficiencia del ordenamiento jurídico y de la identidad nacional.

Como hemos señalado Venezuela se encuentra frente a dos tendencias que se contraponen. La primera consolida el Estado-nación mientras que la segunda promueve la pluriculturalidad y lo multiétnico. La CRBV, forma parte de un proceso complejo - histórico de refundación de la República, en el que es posible apreciar una corriente hacia la homogeneización y otra a la generación de diferencias, heterogeneidad. Señala Segato (2007) que el ideal de la nación es un ciudadano, con un pasado común y un proyecto similar. ${ }^{14} \mathrm{Y}$ este es un detalle, no menor, que se interpela al paradigma constitucional del Estado multiétnico y pluricultural. El Estado-nación moderno nombra la diferencia y la visibiliza, pero en sus términos. El Estado venezolano reconoce a los pueblos indígenas y

...su organización social, política y económica, sus culturas, usos y costumbres, idiomas y religiones, así como su hábitat y derechos originarios sobre las tierras que ancestral y tradicionalmente ocupan y que son necesarias para desarrollar y garantizar sus formas de vida. (Extracto del artículo 119)

El asunto que quiero poner en tensión es si es suficiente con reconocer y declarar un Estado pluricultural y multiétnico. No se trata de garantizar apenas arreglos normativos, se requiere la promoción de prácticas pluriculturales cotidianas. El proceso de reconocimiento de las tierras indígenas debería además aceptar, en función de la pluriculturalidad declarada en la CRBV, otras formas indígenas de derecho territorial. La demarcación es la expresión del derecho, en los términos del Estado-nación

\footnotetext{
${ }^{13}$ Para más detalles sobre este tema véase: Bevilacqua, Mariapia; Cárdenas, Lya y Domingo A. Medina. 2006a.

14 Para mayores detalles con relación a esta idea, véase Anderson (2007) y Segato (2007) y para ver cómo contribuye la cartografía en este isomorfismo también se puede revisar el trabajo de Sharpe (1986).
} 
moderno colonial, pero es necesario preguntarse ¿cuáles son las formas indígenas de ejercer ese derecho?

Las fronteras, límites y demarcaciones son formas jurídicas territoriales que se yuxtaponen sobre las tierras habitadas por los pueblos indígenas ejerciendo violencias en múltiples sentidos. Los indígenas tendrán que apoyarse en el límite establecido en la demarcación para hacer valer sus derechos, a la vez que los mapas, como instrumentos limitados para representar la complejidad de la ancestralidad de la ocupación territorial, pueden sujetar y limitar, como documento legal y técnico, futuras resignificaciones territoriales.

La demarcación territorial Yanomami, también del lado brasilero, y de otros pueblos indígenas, interpela para ponderar esta compleja situación en la que confluyen factores económicos, jurídico-políticos y ambientales yuxtapuestos: las fronteras internacionales entre dos países, los límites nacionales entre dos estados y cuatro municipios, las fronteras de varios tipos de áreas protegidas (Kelly y Carrera, 2007) y los principios de autodemarcación indígena.

\section{Planes y proyectos de desarrollo}

Las tierras indígenas también se ven delimitadas por medio de planes y políticas destinadas al desarrollo y defensa del sur del país. Aunque han sido implementados en distintos momentos históricos, se destacan El plan de la Conquista y Desarrollo del Sur (CodeSur), al comienzo de la década de los setenta del siglo pasado, y el Plan Estratégico Nacional de Desarrollo, Defensa y Consolidación del Sur (PENDDCS), al inicio del siglo XXI.

CodeSur se inscribió dentro de una tendencia continental enmarcada dentro del desarrollo de matriz Cepalina. La conquista y desarrollo del sur fue un plan ideado en el primer gobierno de Rafael Caldera (1969 - 1974). Tenía su fundamento en una visión de la incorporación progresiva de las fuentes de riquezas de la región en el proceso de desarrollo del País. Este plan, luego tuvo su continuidad a lo largo de los años 80 y 90 , en los Programas de desarrollo de la Corporación Venezolana de Guayana (CVG).

De otro lado, el PENDDCS fue ideado con los siguientes objetivos:

1) Desarrollar la capacidad de movilización, intercambio, abastecimiento, interconexión y comunicación del Estado con las comunidades al sur del país en el contexto nacional e internacional. 
2) Garantizar la defensa, seguridad e integridad territorial del sur del país.

3) Reforzar la presencia articulada y coordinada de las instituciones del Estado.

4) Conformar redes de asentamiento cívico militares que sirvan de base para la operatividad del Estado y la atención a las comunidades.

5) Atender progresivamente las necesidades sociales prioritarias de las comunidades donde estuvo asentada la Misión Nuevas tribus y otras seleccionadas. ${ }^{15}$

Estos dos planes, responden por un lado a la necesidad de consolidar la presencia del Estado-nación venezolano, frente a la profunda vocación expansionista de países como Brasil. Mientras que, por otro lado, la presencia del Estado pretende salvaguardar las fronteras, proteger a las comunidades indígenas, evitar masacres y atropellos. Es importante preguntar si ¿estos planes de desarrollo seguridad y defensa consideran la perspectiva indígena?

En la revisión de la literatura asociada a los mismos no se encuentra referencia alguna al etnodesarrollo. Nuevamente la modernidad/ colonialidad se despliega ofreciendo un desarrollo y defensa mientras que se dejan de lado la voz y punto de vista de los pueblos indígenas. El desarrollo y la modernidad para el Estado-nación y para las áreas ocupadas por los pueblos indígenas en contextos fronterizos se difunde marginalizando las visiones de esos pueblos para sus territorios.

\section{Un modelo de demarcación para un modelo de territorio}

Otra reflexión sobre el proceso de demarcación de tierras indígenas se deriva de la autodemarcación de tierras llevada a cabo por los pueblos indígenas Jodi y Eñepa. Este proceso se inicia con una solicitud de ayuda expresa hecha por los propios indígenas a los antropólogos Stanford Zent y Egleé López-Zent ${ }^{16}$, quienes con anterioridad habían realizado investigaciones entre los Jodi.

Luego de concluir su trabajo estos antropólogos plantean, entre otros aspectos, que los significados indígenas Jodi y E'ñepaque trascienden los requerimientos solicitados por el Estado para garantizar los títulos de

\footnotetext{
${ }^{15}$ Para mayores detalles sobre el PENDDCS véase: Gómez y Márquez. 2009.

${ }^{16}$ Para mayores detalles sobre esta fase de la demarcación Jodi y E’ñepa véase López Zent, Zent y Marius, 2003 así como Zent y López Zent, 2006.
} 
propiedad colectiva sobre la tierra (Zent y López Zent, 2006). En especial enfatizan las implicaciones que tiene la demarcación estatal para estos pueblos indígenas:

¿Es adecuado contar con un solo modelo de territorio fijo para grupos humanos dinámicos que difieren considerablemente en términos de su patrón de ocupación, uso, manejo de recursos, y construcción conceptual de la tierra? (Zent y López Zent, 2006:70)

Los E'ñepa en comparación con los Jodi, son caracterizados, como horticultores, con un patrón de asentamiento sedentario, con un concepto de territorio más fijo y con una idea de la propiedad y exclusividad de su territorio. Mientras que los Jodi en comparación como los E'ñepa son definidos como forrajeros, con un patrón de asentamiento más nómada, un concepto de territorio más fluido y una noción de propiedad compartida. Frente a tal caracterización Zent y López Zent (2006) se plantean:

Nos parece que tales diferencias pueden relacionarse en un nivel conceptual más profundo con dos tipos de vida/paisaje (o lifescape/landscape) contrastantes que abarca pero trasciende la mera distinción entre agricultor y forrajero: por un lado, un ethos de relacionalidad con el mundo marcado por la constancia relativa en el tiempo-espacio y la conectividad ordenada entre los diferentes seres, por otro lado, un ethos de relacionalidad fundamentada en el movimiento, el cambio y la interconectividad relativa entre los seres. Si resulta correcta nuestra interpretación, entonces podemos suponer que la demarcación y titulación de tierras y hábitats fijos podrian tener efectos diferentes para las vidas/paisajes de esos grupos. ¿Cómo podría hacerse una política de tierras indígenas que tome en cuenta la diversidad biocultural de los países y que también provea una solución justa y equitativa ante las necesidades territoriales de todos? Ese es el dilema (Zent y López-Zent, 2006:93).

Las experiencias de los Jodi y E'ñepa permite poner en evidencia cómo estas demarcaciones de tierras indígenas y la producción de mapasimagen-representación, responden más a la lógica del Estado-nación que a las perspectivas indígenas. Adecuadas al fundamento de un solo territorio, un pueblo y una identidad marginalizan la diversidad multiétnica proclamada en el preámbulo de la CRBV. ¿Cómo se puede implementar una política pública dialógicamente? La pregunta va más allá de la creación de 
instituciones como el Ministerio para los pueblos indígenas y de las leyes creadas. ¿Es posible el diálogo intercultural entre el Estado y los pueblos indígenas?

Estamos ante una paradoja: la modernidad/colonialidad suprime e impone una manera de ver actuando de soslayo a la retórica emancipadora de la modernidad, la que apela y promueve los derechos. El Estado - nación nombra la diferencia y la visibiliza, pero en sus términos. A partir del reconocimiento de las culturas de los pueblos indígenas, ¿es posible ir más allá de la cartografía y establecer una cartografía otra? Estas cartografías, me refiero a la del Estado-nación y una posible cartografía indígena, ¿pueden entrar en diálogo? ¿Se puede hacer una cartografía pluricultural siendo la cartografía en sí misma un dispositivo moderno colonial? ¿Desde la pluriculturalidad puede haber otra alternativa a la demarcación y a los mapas?

La coyuntura generada por las demarcaciones de tierras indígenas es ideal para propiciar la emergencia de perspectivas indígenas, pero ¿cómo huir del riesgo de cosificarlas? ¿Cómo trascender la modulación los dispositivos geoepistemológicos, geopolíticos y geohistóricos de la hybris del punto cero, la función centro de la modernidad/colonialidad, que actúan desde la cartografía?

\section{Conclusiones}

En este artículo señalo algunas de las paradojas geopolíticas y geoepistémicas que acompañan el caso venezolano de demarcación de tierras indígenas. La paradoja geopolítica comienza cuando se intenta implementar un derecho a través de una estructura, moderna-colonial como lo es el Estado-nación con la imposición de sus formas, leyes, derechos, demarcaciones, maneras de conocer, etc., desconociendo las formas indígenas. La paradoja geoepsitémica es que se quiera reconocer un derecho en un Estado-nación que opera desde la colonialidad y la hybris del punto cero. Es decir, a través de una manera única y legitimada - la del Estado-nación, con sus demarcaciones, mapas y en detrimento de otras formas múltiples, por ejemplo, las de los pueblos indígenas.

El debate decolonial permite repensar estas estructuras, discursos y prácticas moderno-coloniales imbuidas de colonialidad, hybris del punto cero y función centro mediante una reflexión geoepistémica y geopolítica. Sin embargo, se debe tener en cuenta que se le hace un flaco favor a la causa indígena, que nos interesa por encima de todo, cuando no se considera que dentro del sistema mundo-moderno-colonial, en el cual se inscribe la figura 
del Estado-nación operan simultáneamente, el intento por reconocer los derechos indígenas e implementarlos, a la vez, que se generan y reproducen las condiciones de explotación y acumulación de un modelo extractivista de recursos en nombre del desarrollo de la nación y en muchos casos en perjuicio de la territorialidad indígena.

En nuestro caso, el Estado-nación reconoció el derecho de los pueblos indígenas, pero con sus condiciones. Condiciones que superan al Estado venezolano ya que son geopolíticas y geohistóricas; trata de contradicciones propias a la conformación del Estado-nación-moderno. La revisión del proceso de demarcación de tierras y sus implicaciones jurídico-culturales a través de las conceptualizaciones y categorías del debate decolonial elucida sobre la urgencia de repensar al propio Estado.

Esta revisión y crítica es indispensable, pero se debe hacer a la par de una defensa de los pueblos indígenas, de sus formas de conocer, sus territorios, y hasta del Estado-nación, ya que paradójicamente, esta formación histórica constituye el marco jurídico-político-social-cultural e histórico, más eficaz, instrumental y operativo -hasta ahora - para reconocer, desarrollar y exigir el cumplimiento de los derechos colectivos indígenas, así como para defender la vida. Es el Estado-nación el que permite defender a los pueblos indígenas de los avances criollos nacionales y extranjeros, propiciados por la modernidad/colonialidad y el sistema mundo modernocolonial del cual tanto el Estado-nación y el sistema de explotación forman parte. Esta es la gran paradoja.

El debate decolonial, a través de sus categorías analítico-interpretativas permite poner en evidencia como el Estado-nación ejerce una función centro que le permite erigir una sola estructura para el reconocimiento e implementación de los derechos de los pueblos indígenas. Esta reflexión permite develar que en paralelo, se imponen las condiciones para que el Estado-nación por su vinculación histórica al sistema mundo-moderno colonial, module las voces y prácticas indígenas, al impregnarlas de una sola perspectiva o manera de hacer y conocer y dejando de lado la diversidad de respuestas que podrían dar los pueblos indígenas.

La paradoja es que emerja el debate decolonial y que mediante su crítica, necesaria e indispensable, se debiliten los discursos y prácticas del Estadonación, así como sus maneras necesarias para la defensa de las poblaciones, conocimientos, recursos y tierras. Especialmente si recordamos que hoy más que nunca los pueblos indígenas se ven afectados por los avances sobre tierras indígenas de corporaciones nacionales como Petróleos de Venezuela, PDVSA y la Corporación Venezolana de Guayana, 
CVG; y transnacionales del petróleo, así como los mineros locales y los garimpeiros. ${ }^{17}$

Partir de la reflexión decolonial para abordar el proceso de la demarcación de las tierras indígenas en Venezuela permite apreciar no sólo los condicionamientos epistémicos y políticos sino las paradojas que se derivan de estos condicionamientos que son históricos. El Estado multiétnico y pluricultural debe ser algo más que un decreto. Se deben establecer y desarrollar formas de relaciones dialógicas entre el Estadonación y los pueblos indígenas que promuevan las prácticas pluriculturales cotidianas que permitan la emergencia de la perspectiva indígena.

\section{Agradecimientos}

Este trabajo es una versión ampliada de la ponencia presentada en el simposio: Estados plurinacionales, territorios y autodeterminación indígena. El desafío epistemológico de la reflexión decolonial como aporte al pensamiento indigenista en América Latina y las prácticas interculturales en el marco de problemáticas territoriales del Primer Congreso Internacional de los Pueblos Indígenas de América Latina, Siglos XIX-XXI. Avances, Perspectivas y Retos, realizado entre el 28 y 31 de octubre de 2013 en la ciudad de Oaxaca, México. Quiero agradecer a la coordinadora de este simposio, la profesora Sandra Nascimento, así como los ponentes, la oportunidad para compartir experiencias, conocimientos e ideas sobre la realidad de nuestros trabajos. El Fondo Nacional de Ciencia, Tecnología e Innovación, FONACIT de Venezuela financió los gastos de asistencia al mencionado Congreso. La versión inicial de este trabajo está contenida en mi tesis de maestría en Estudios Culturales por la UARCIS de Santiago de Chile, año 2010, le doy las gracias por su apoyo y orientaciones a mi tutor el Profesor Cristián Gómez Moya.

Asimismo, agradezco a mis compañeros del Laboratorio de Antropología del Desarrollo del Instituto Venezolano de Investigaciones Científicas, IVIC, especialmente a la Dra. Hortensia Caballero Arias, Dra. Krisna Ruette y al

\footnotetext{
${ }^{17}$ El desarrollo minero se propicia desde las más altas esferas del Ejecutivo nacional: el 27 de febrero de 2012, el gobierno de Venezuela, firmó una serie de convenios con el Gobierno Chino que incluyen entre otros aspectos el desarrollo de actividades de exploración y explotación de minerales en la región Guayana y en la Faja petrolífera del Orinoco. Los convenios los firma la República de Venezuela con la empresa CITIC. Ese mismo año a pocos días de las últimas elecciones en las que Hugo Chávez fue presidente-candidato: se firmó un acuerdo entre la empresa gubernamental venezolana INGEOMIN y la empresa trasnacional china CITIC con la finalidad de desarrollar un mapa minero que permita la certificación y cuantificación de las reservas minerales de todo el país. véase: Asamblea Vicarial. (2013)
} 
Dr. Javier Carrera Rubio el debate sistemático de los temas planteados en el marco de nuestro trabajo diario.

\section{Bibliografía}

AGUILAR CASTRO, Vladimir. Territorios indígenas y demarcación en Venezuela: de la responsabilidad jurídica a la banalización política. Grupo de Trabajo sobre Asuntos Indígenas (GTAI). Universidad de Los Andes, Mérida-Venezuela. Mimeo. 2012

ANDERSON, Benedict. Comunidades Imaginadas: Reflexiones sobre el origen y la difusión del nacionalismo. México: Fondo de Cultura Económica. 2007.

ASAMBLEA VICARIAL. ¿Qué pasa en Amazonas? Elementos para la Pastoral Social del Vicariato. La Iglesia en Amazonas. (Revista ilustrada trimestral del Vicariato Apostólico de Puerto Ayacucho, estado Amazonas, Venezuela). (140): pp.10-25, 2013.

BELLO, Luis Jesús. El reconocimiento constitucional de la existencia de los pueblos y comunidades indígenas y de los derechos originarios sobre las tierras que ocupan. Proceso de demarcación de hábitat y tierras indígenas y garantía del derecho a la porpiedad colectiva (Art. 119 CRBV) En: BELLO, Luis Jesús (Ed.). El Estado ante la sociedad multiétnica y pluricultural. Políticas públicas y derechos de los pueblos indígenas en Venezuela (1999 - 2010). Caracas: Wataniba - IWGIA, pp: 35 -96, 2011

BERNAL RODRÍGUEZ, Yheicar. Etnocartografía escópica moderno colonial: Indígenas Antropólogos y Estado venezonalo. Santiago de Chile: UARCIS. (Tesis presentada para optar al grado de Magíster en Estudios Culturales), 2010.

BEVILACQUA, Mariapia; CÁRDENAS, Lya.; MEDINA, Domingo A. Las áreas protegidas en Venezuela: Diagnóstico de su condición 1993 / 2004. Caracas: Fundación Empresas Polar, ACOANA, UICN, 2006a.

BEVILACQUA, Mariapia; MEDINA, Domingo A.; CÁRDENAS, Lya. Manejo de recursos comunes en áreas protegidas, tierras y hábitats indígenas en Venezuela: pensando más allá de los procesos de demarcación. Antropológica, (Revista del Instituto Caribe de Antropología y Sociología, Fundación La Salle de Ciencias Naturales, Caracas) (105-106): pp.161-184, 2006b.

CABALLERO ARIAS, Hortensia; CARDOZO, Jesús Ignacio. Políticas territoriales, memoria histórica e identidad: los Yanomami ante la 
demarcación de sus tierras. Antropológica, (Revista del Instituto Caribe de Antropología y Sociología, Fundación La Salle de Ciencias Naturales, Caracas) (105-106): pp. 99-130, 2006.

CABALLERO ARIAS, Hortensia. La demarcación de tierras indígenas en Venezuela. Revista Venezolana de ciencias sociales, 13(3), pp.189-208, 2007.

CASTRO-GÓMEZ, Santiago. Ciencias Sociales, violencia epistémica y el problema de la invención del otro. En: LANDER, Edgardo (Comp.) La colonialidad del saber: eurocentrismo y ciencias sociales. Perspectivas Latinoamericanas Buenos Aires: CLACSO. pp.145-161, 2000.

La hybris del punto cero: ciencia, raza e ilustración en la Nueva Granada (1750-1816). Bogotá: Pontificia Universidad Javeriana, 2005a.

La Poscolonialidad explicada a los niños. Popayán: Universidad del Cauca, Instituto Pensar, Universidad Javeriana, 2005b.

CASTRO-GÓMEZ, Santiago.; GROSFOGUEL, Ramón. "Prólogo: Giro decolonial, teoría crítica y pensamiento heterárquico". En: CASTRO-GÓMEZ, Santiago.; GROSFOGUEL, Ramón (Eds.). El giro decolonial: reflexiones para una diversidad epistémica más allá del capitalismo global Bogotá: Siglo del hombre editores, pp. 9-23, 2007.

CLARAC, Jacqueline. Análisis de las actitudes de políticos criollos e indígenas en Venezuela (De los años 60 hasta el 2001). Boletín Antropológico. (Boletín del Centro de Investigaciones Etnológicas - Museo Arqueológico, Universidad de Los Andes, Mérida), (53): pp. 335 - 372, 2001.

DUSSEL, Enrique. "Europa, modernidad y eurocentrismo". En: LANDER, Edgardo (Ed.), La colonialidad del saber: eurocentrismo y ciencias sociales Perspectivas latinoamericanas Buenos Aires: CLACSO, pp.41-53, 2000.

DE CERTEAU, Michel. La invención de lo cotidiano 1: Artes de hacer. México: Universidad Iberoamericana. 2007.

ESCOBAR, Arturo. "Mundos y conocimientos de otro modo": El programa de investigación de modernidad/colonialidad latinoamericano. Tabula Rasa (1), pp.51-86, 2003.

GÓMEZ, Luis Ernesto.; MÁRQUEZ, Humberto. Entrevista al General Ascanio Tovar/Coordinador del PENDDCS. Revista Amazonía. (Publicación del Parlamento Amazónico, Caracas) (4): pp. 40-45, 2009.

HERNÁNDEZ, Francisco. Las comunidades indígenas en Venezuela y el problema de la tenencia de la tierra. En: JIMÉNEZ, Simeón; PEROZO, Abel (eds.). Esperando a Kuyujani: Tierras, leyes y autodemarcación. Encuentro de 
comunidades Ye'kuanas del Alto Orinoco. Caracas: Asociación otro Futuro, GAIA, IVIC. pp. 45-68, 1994.

Derechos Indígenas en la Constitución de la República Bolivariana de Venezuela de 1999. Caracas: Ministerio de Educación Cultura y Deportes, 2001.

JIMÉNEZ, Simeón.; PEROZO, Abel. Esperando a Kuyujani: Tierras, leyes y autodemarcación. Encuentro de comunidades Ye'kuanas del Alto Orinoco. Caracas: Asociación Otro Futuro. GAIA - IVIC. 1994.

KELLY, José Antonio.; CARRERA RUBIO, Javier. Los Yanomami: relaciones con la biomedicina. En: FREIRE, Germán.; TILLETT, Aimett (Eds.). Salud Indígena en Venezuela. Volumen I. Caracas: Dirección de Salud Indígena del Ministerio del Poder Popular para la Salud y el Instituto Caribe de Antropología y Sociología, Fundación La Salle. pp 325 -381, 2007.

LANDER, Edgardo. Ciencias sociales: saberes coloniales y eurocéntricos. En: LANDER, Edgardo. (Ed.). La colonialidad del saber: eurocentrismo y ciencias sociales, perspectivas latinoamericanas Buenos Aires: CLACSO. pp. 11-40, 2000.

LÓPEZ ZENT, Eglée.: ZENT, Stanford.; MARIUS, Leticia. Autodemarcando la Tierra: Explorando las ideas, los árboles y caminos Hoti. Boletín Antropológico (59): pp. 313-338, 2003.

MIGNOLO, Walter Historias Locales / Diseños globales, Colonialidad, conocimientos subalternos y pensamiento fronterizo. Madrid: Akal, 2003.

La idea de América Latina: La herida colonial y la opción decolonial. Barcelona: Gedisa, 2007.

QUIJANO, Aníbal. "Colonialidad del poder, eurocentrismo y América Latina". En: LANDER, Edgardo. (Eds.): La colonialidad del saber: eurocentrismo y ciencias sociales Perspectivas latinoamericanas Buenos Aires: CLACSO, pp. 201-246, 2000.

REPÚBLICA BOLIVARIANA DE VENEZUELA. Constitución de la República Bolivariana de Venezuela. Caracas: Gaceta oficial, 1999.

Ley de Demarcación y Garantía del Hábitat y Tierras de los Pueblos Indígenas. Caracas: Gaceta Oficial No. 37.118. 12 de enero de 2001.

Decreto presidencial No. 1392 mediante el cual se crea la comisión nacional de demarcación de tierras y hábitats de pueblos y comunidades indígenas. Caracas: Gaceta Oficial No. 37.257. 09 de agosto de 2001. 
Ley Orgánica de Pueblos y Comunidades Indígenas. Caracas: Gaceta Oficial No. 38.344 . 27 de diciembre de 2005.

Ley de patrimonio cultural de los pueblos y comunidades indígenas. Caracas: Gaceta Oficial No.39.115. 06 de febrero de 2009.

RESTREPO, Eduardo. "Antropología y colonialidad". En: CASTRO-GÓMEZ, Santiago.; GROSFOGUEL, Ramón (Eds): El giro decolonial: Reflexiones para una diversidad epistémica más allá del capitalismo global (págs. 289-304). Bogotá: Siglo del hombre editores, 2007.

Debate decolonial: fuentes, conceptos y cuestionamientos. Popayán: Universidad del Cauca, Instituto de Estudios Sociales y Culturales Pensar, 2010.

RICHARD, Nelly. Intersectando Latinoamérica con el latinoame-ricanismo: discurso académico y crítica cultural. En: CASTRO-GÓMEZ, Santiago.; MENDIETA, Eduardo. (eds.) Teorías sin disciplina. Latinoamericanismo,poscolonialidad y globali-zación en debate. México: Porrúa - University of San Francisco. pp. 245-270. 1998.

"Globalización académica, estudios culturales y crítica latinoamericana". En: MATO, Daniel (Ed.), Cultura, política y sociedad: Perspectivas latinoamericanas. Buenos Aires: CLACSO, pp. 455-470, 2005.

SEGATO, Rita Laura. En busca de un léxico para teorizar la experiencia territorial contemporánea. En: SEGATO, Rita Laura. La Nación y sus Otros: Raza, etnicidad y diversidad religiosa en tiempos de política de identidad . Buenos Aires: Prometeo Libros. págs. 71-98, 2007.

SHARPE, Barrie. Ethnography and a Regionalism System: Mental Maps and the Myth of States and Tribes in North-Central Nigeria. Critique of Anthropology. Vol. 6. (3) pp. $33-65,1986$.

SILVA MONTERREY, Nalúa. Reconocimientos territoriales indígenas y soberanía del Estado en Venezuela. Kuawäi (Universidad Nacional Experimental de Guayana, Centro de Investigaciones Antropológicas de Guayana, Departamento Hombre y Ambiente). Enero - junio. Vol. 2 (3): pp.32-46, 2009.

WALLERSTEIN, Immanuel. El moderno sistema mundial I: la agricultura capitalista y lo orígenes de la economía-mundo europea en el siglo XVI. (Vol. 1). México: Siglo XXI, 1991.

WALLERSTEIN, Immanuel. "El eurocentrismo y sus avatares. Los dilemas de la ciencia social". En: Mignolo, Walter (Ed.): Capitalismo y geopolítica del 
conocimiento. El eurocentrismo y la filosofía de la liberación en el debate intelectual contemporáneo Buenos Aires: Ediciones del Signo/Duke. pp. 95$115,2001$.

ZENT, Stanford.; LÓPEZ-ZENT, Eglée. Más allá de la demarcación de tierras indígenas: comparando y contrastando las etnocartografías de agricultores y cazadores - recolectores. Antropológica (Instituto Caribe de Antropología y Sociología, Fundación La Salle, Caracas.) (105-106): pp. 67-98, 2006. 